\title{
A randomized comparison between misoprostol and dinoprostone for cervical ripening and labor induction in patients with unfavorable cervices
}

\author{
Aparajita Sophia D'souza ${ }^{1 *}$, Clarence J. Samuel ${ }^{2}$, Francis Sridhar Katumalla ${ }^{3}$, Garima Gupta $^{1}$, \\ Sunita Goyal ${ }^{1}$
}

${ }^{1}$ Department of Obstetrics \& Gynaecology, Christian Medical College, Ludhiana, Punjab, India

${ }^{2}$ Department of Community Medicine, Christian Medical College, Ludhiana, Punjab, India

${ }^{3}$ Department of Urology, Christian Medical College, Ludhiana, Punjab, India

Received: 01 September 2015

Accepted: 09 September 2015

\section{*Correspondence:}

Dr. Aparajita Sophia D’souza,

E-mail: dsouzaaparajita@yahoo.in

Copyright: (c) the author(s), publisher and licensee Medip Academy. This is an open-access article distributed under the terms of the Creative Commons Attribution Non-Commercial License, which permits unrestricted non-commercial use, distribution, and reproduction in any medium, provided the original work is properly cited.

\begin{abstract}
Background: The induction of labor remains as one of the major challenges in obstetrics even in this modern era. The ideal priming agent is one that causes cervical change that is most similar to that seen in natural ripening process. This study was aimed to evaluate the safety and efficacy of intravaginal Misoprostol and compare its effects with intracervical dinoprostone gel for cervical ripening and labor induction in patients with unfavourable uterine cervices. Methods: This was a one-year prospective study conducted in the department of Obstetrics and Gynecology of a 800 bedded premier teaching hospital in Ludhiana. The study population consisted of all pregnant women admitted to the labor ward beyond 37 weeks of gestation and requiring induction of labor for various medical and obstetrical indications. Frequencies, proportions, mean and standard deviation were done while chi square and t-test were used for determination of significance.

Results: A total of 153 mothers fulfilled the criteria to be included in the study of which 81 mothers were induced by misoprostol and 72 mothers by dinoprostone gel respectively. There was no statistical difference in the maternal age, parity and gestation at the onset of study in the two groups. The ANC complications were also statistically similar. There was no significant difference in the mean initial Bishop Score in the two groups. 3.42 in the Misoprostol group and 3.56 in the Dinoprostone group. The mean Bishop Score after 8 hour of the first dose was 7.86 in the Misoprostol group and 6.88 in the Dinoprostone group. The mean time taken from the induction to the onset of labor was 5.57 hours in the misoprostol group and 8.04 hours in the dinoprostone group. There were no cases of tachysystole or hyperstimulation in both the groups.

Conclusions: Misoprostol is a more efficacious cervical ripening and labor inducing agent compared to dinoprostone gel and can be used safely in the North Indian setting.
\end{abstract}

Keywords: Misoprostol, Dinoprostol, Induction of labour, Cervical ripening 


\section{INTRODUCTION}

The induction of labor remains as one of the major challenges in obstetrics even in this modern era. ${ }^{1}$ Induction of labor implies artificial initiation of regular uterine contractions before their spontaneous onset, after twenty-eight weeks of gestation by a method that aims secure delivery "per vias naturales". ${ }^{2}$ The cervix serves two major functions in pregnancy. First, it maintains its firmness, i.e. physical integrity, during pregnancy as the uterus enlarges dramatically, until the appropriate time for delivery.

Second, in preparation for parturition the cervix softens, effaces and becomes more stretchable referred to as cervical ripening. These changes are required for the safe delivery of fetus with minimal stress and trauma.

The presence of cervical ripening is of fundamental importance for a successful induction of labor. It involves highly complex biochemical processes

Numerous methods have been used to promote cervical ripening, from the less orthodox - breast stimulation, sexual intercourse, a variety of herbs, castor oil, enemas and acupuncture - to more orthodox methods, such as stripping the membranes, mechanical dilatation, amniotomy and use of pharmacologic preparations. ${ }^{4}$

The ideal priming agent is one that causes cervical change that is most similar to that seen in natural ripening process and does not affect uterine blood flow or the fetoplacental unit. It should not affect the maternal wellbeing nor inflict any cervical injury or uterine rupture. ${ }^{5}$

Induction of labor with prostaglandins offers the advantage of promoting cervical ripening while stimulating myometrial contractility. ${ }^{6}$ The use of prostaglandin analog misoprostol has been gaining wider acceptance due to its safety profile and handling.

This study was aimed to evaluate the safety and efficacy of intravaginal Misoprostol and compare its effects with intracervical Dinoprostone gel for cervical ripening and labor induction in patients with unfavourable uterine cervices.

\section{METHODS}

This was a one-year prospective study conducted in the Department of Obstetrics and Gynecology of a 800 bedded premier teaching hospital Ludhiana. The study was approved by the Research and Ethics Committee of the Hospital. The study population consisted of all pregnant women admitted to the labor ward beyond 37 weeks of gestation and requiring induction of labor for various medical and obstetrical indications. Both booked and unbooked mothers were included in this study. Booked antenatal women were those who had three or more check-ups in the institution during antenatal period.

\section{Inclusion criteria}

1. Unfavourable cervix i.e. Bishop Score of 6 or less

2. Patients not in labor

3. Singleton pregnancy

4. Cephalic presentation

5. Intact membranes

6. Reactive NST

\section{Exclusion criteria}

1. Placenta previa or unexplained vaginal bleeding.

2. Any contraindications for receiving Prostaglandins including history of asthma, glaucoma or preexisting cardio-vascular disease.

3. Renal or hepatic dysfunction

4. Parity more than five

5. Intrauterine death

The participants were then matched according to parity and allocated into two groups. The first group received Misoprostol $\left(\mathrm{PGE}_{1}\right)$ for induction and the second group was induced with dinoprostone gel $\left(\mathrm{PGE}_{2}\right)$. The subjects underwent an admission history and physical examination.

Clinical pelvimetry was done to determine the type of the pelvis and to assess its adequacy for the baby.

Bishop Scoring was done according to the vaginal examination findings and those with a Bishop Score of 6 or less were included in the study.

A 20 minutes external (abdominal) cardiotocographic monitoring was done and a non-stress test (NST) was performed. Two or more fetal heart rate accelerations of 15 or more beats per minute lasting for 15 or more seconds with fetal movements or activity in a 20 minutes period was interpreted as a reactive NST. The respective cervical ripening and labor inducing agent was then applied.

\section{Procedure}

Group I - Misoprostol was prepared by cutting the 100 $\mu \mathrm{gm}$ tablets in half.

A gentle per vaginal examination was done and a deliberate attempt was made to avoid excessive cervical manipulation, to avoid releasing endogenous prostaglandins. The $50 \mu \mathrm{gm}$ misoprostol tablet was then placed digitally in the posterior fornix.

Group II - Dinoprostone gel $\left(\mathrm{PGE}_{2}\right)$ - Dinoprostone gel $0.5 \mathrm{mg}$ is available in a prefilled plastic syringe.

The cervix was exposed by Sim's speculum. The tip of the prefilled $\mathrm{PGE}_{2}$ syringe was placed in the cervical canal just below the internal os and the gel was introduced in the cervical canal. The catheter was slowly 
withdrawn while introducing the gel to avoid extra amniotic application.

In both the groups, the patients were asked to lie supine for one hour. The vital signs of the patient were monitored at hourly intervals for two hours and then at four hourly intervals thereafter. Uterine contractions and fetal heart rate were recorded every 15 minutes. Any side effects like hypertonic contractions, vomiting, fever or change in fetal heart rate was also noted.

A repeat vaginal examination and Bishop Scoring was done at the end of 8 hours by the same doctor in order to maintain uniformity in examination. The drug was repeated if the Bishop Score was still 6 or less and if there were no regular uterine contractions. A maximum of three doses of the drug was used.

Once in the active phase, routine intrapartum management occurred without regard to the study drugs. Artificial rupture of membranes (ARM) was generally performed when the cervix was $80 \%$ effaced and $\geq 3 \mathrm{~cm}$ dilated. Patients who did not enter active labor after receiving the maximum dose, had spontaneous rupture of membranes without an ensuring adequate contractile pattern, or who had an arrest of dilatation in active labor received intravenous oxytocin augmentation.

The duration from the time of induction to the onset of labor was noted. During the first stage of labor uterine contractions and FHR was recorded every 15 minutes and any abnormalities like tachysystole, hypertonus, hyperstimulation were noted. Maternal blood pressure and pulse were recorded every two hours. After ARM the colour of liquor was seen. The need for oxytocin augmentation and the maximum amount of oxytocin required was noted.

Statistical analysis used: Frequencies, proportions, mean, standard deviation were calculated while chi square and t-test were used to test of significance.

\section{RESULTS}

A total of 153 mothers fulfilled the criteria to be included in the study of which 81 mothers received misoprostol and 72 mothers received dinoprostone gel for induction of labor. The age distribution, educational background, parity and period at gestational were similar (Table 1).

Most in both the groups were booked antenatal mothers with (3 or more antenatal visits to $\mathrm{CMCH}$ ), while only seven women $(8.6 \%)$ were unbooked in the misoprostol group and 11 women $(15.3 \%)$ in the dinoprostone group.

In the women receiving misoprostol, 29 women $(35.8 \%)$ had 3-6 ANC visits and $45(55.6 \%)$ had $>6$ ANC visits to $\mathrm{CMCH}$ while in dinoprostone group the mothers 15 $(20.8 \%)$ had 3-6 visits and $46(63.9 \%)$ had > 6 visits respectively. Associated antenatal complications were present in $44(54.32 \%)$ of the 81 women induced with misoprostol and in $31(43.06 \%)$ of the 72 women receiving dinoprostone respectively. A few women had more than one ANC complication. The most common antenatal complication was PIH $16(19.75 \%)$ women in misoprostol group and in $10(13.89 \%)$ women receiving dinoprostone. One mother in misoprostol group and five mothers $(6.94 \%)$ in Dinoprostone group had previous caesarean sections. Twenty-six women $(32.10 \%)$ in the misoprostol group and 30 women $(41.67 \%)$ in the dinoprostone group were induced in view of term pregnancy. Twenty-four mothers $(29.63 \%)$ in the misoprostol group and 20 mothers (27.78\%) in dinoprostone group had post term pregnancy as the indication for the intervention. PIH was the next common indication for induction being $19.75 \%$ (16) in the misoprostol group and $13.89 \%$ (10) among the mothers who received dinoprostone.

Table 1: Demographic characteristics of women by the interventional groups.

\begin{tabular}{|c|c|c|c|c|}
\hline & $\begin{array}{l}\text { Misoprostol } \\
\mathrm{N}=\mathbf{8 1} \text { n (\%) }\end{array}$ & $\begin{array}{l}\text { Dinoprostone } \\
\mathrm{N}=72 \text { n }(\%)\end{array}$ & $\begin{array}{l}\text { Chi } \\
\text { Square }\end{array}$ & $\begin{array}{l}P \text { - } \\
\text { value }\end{array}$ \\
\hline $\begin{array}{l}\text { Age gp } \\
15-20 \text { yrs. } \\
21-25 \text { yrs. } \\
26-30 \text { yrs. } \\
31-35 \text { yrs. } \\
>35 \text { yrs. } \\
\text { Mean } \pm \text { SD }\end{array}$ & $\begin{array}{l}3(3.7) \\
43(53.1) \\
31(38.3) \\
4(4.9) \\
0(0.0) \\
25.27 \pm 3.07\end{array}$ & $\begin{array}{l}1(1.4) \\
36(50.0) \\
29(40.3) \\
5(6.9) \\
1(1.4) \\
25.79 \pm 3.40\end{array}$ & 0.177 & 0.68 \\
\hline $\begin{array}{l}\text { Education } \\
\text { Illiterate } \\
\text { Primary } \\
\text { High } \\
\text { School } \\
\text { Graduate } \\
\text { and above }\end{array}$ & $\begin{array}{l}1(1.2) \\
1(1.2) \\
29(35.9) \\
50(61.7)\end{array}$ & $\begin{array}{l}0(0.0) \\
3(4.2) \\
38(52.7) \\
31(43.1)\end{array}$ & 7.161 & 0.067 \\
\hline $\begin{array}{l}\text { Parity } \\
\text { Primi } \\
\text { Multipara }\end{array}$ & $\begin{array}{l}32(39.51) \\
49(60.49)\end{array}$ & $\begin{array}{l}30(41.67) \\
42(58.33)\end{array}$ & $\begin{array}{l}0.07 \\
0.788\end{array}$ & \\
\hline $\begin{array}{l}\text { Period of } \\
\text { Gestation } \\
\text { 37-38 Wks. } \\
\text { 38-39 Wks. } \\
\text { 39-40 Wks. } \\
\text { 40-41 Wks. } \\
\text { Mean } \pm \text { SD }\end{array}$ & $\begin{array}{l}16(19.8) \\
20(24.7) \\
21(25.9) \\
24(29.6) \\
39.19 \pm 1.19\end{array}$ & $\begin{array}{l}11(15.3) \\
10(13.9) \\
31(43.1) \\
20(27.7) \\
39.44 \pm 1.02\end{array}$ & 5.98 & 0.112 \\
\hline
\end{tabular}

The mothers induced with misoprostol, at the start of induction had a mean Bishop Score of 3.03. After 8 hours, the mean score was found to be 7.26, showing a mean change of 4.29 , which was a statistically significant change $(\mathrm{p}<0.01)$.

The mean Bishop Score in the dinoprostone group of mothers at the time of induction was 3.23, which increased to a mean of 6.14 , $(p<0.01)$.showing a mean change of 3.00 in the score after 8 hours of application of the first dose of dinoprostone. 
On comparing the two drugs, there was no significant difference in the initial Bishop Score $(p>0.10)$. The second Bishop Score after 8 hour of application of the drug was significantly higher in the women induced with misoprostol $(\mathrm{p}<0.01)$.

In the misoprostol group, 68 women $(83.95 \%)$ required only one dose and 12 women $(14.82 \%)$ received 2 doses. Only one patient had to be induced with three doses.

In the Dinoprostone group, 52 women $(72.22 \%)$ required only one dose, 15 women $(20.83 \%)$ required two doses and in five women (6.94\%) three doses were used. Mean dose was 1.35 per woman.

Of the 81 women induced with misoprostol, 12 (14.82\%) patients were augmented with oxytocin while 28 patients $(38.89 \%)$ in the dinoprostone required augmentation.

Oxytocin requirement was significantly higher in the Dinoprostone group of women $(\mathrm{p}<0.01)$.

The mean duration between induction and delivery among the primigravidae mothers in the misoprostol group was $15.46 \pm 5.99$ and in the dinoprostone $18.27 \pm$ $8.41(\mathrm{t}=1.97123 \mathrm{p}$ value $=0.002)$. The mean duration between induction and delivery in multigravidae misoprostol group $10.41 \pm 4.84$ and in the dinoprostone $15.1 \pm 7.06(\mathrm{t}=2.12774, \mathrm{p}$ value $<0.001)$.

The incidence of LSCS was $11.11 \%$ in the Misoprostol group as compared to $16.67 \%$ in the Dinoprostone group. There was no significant difference in the incidence of caesarean section in the two groups as listed in table No 4. LSCS was performed mainly because of meconium staining of liquor. Arrest disorders were the second most common indication for LSCS. There was no significant difference in the incidence of indications in the two groups. Meconium staining of liquor was seen in $4.94 \%$ in the Misoprostol group and $6.94 \%$ in the Dinoprostone group which was not significantly different. The mean birth weights in the two groups were similar (2981.35 gm in the misoprostol group and $2981.13 \mathrm{gm}$ in the dinoprostone group).

\section{DISCUSSION}

The demographics of the study population, parity, gravidae and the gestational age at intervention are similar to other studies. ${ }^{7-12}$ The lesser mean age of women, in the current study can be explained due to the fact that in India the age of marriage is much lower than that of the western countries. The larger number of primigravida in the study conducted by Buser et al., is probably due to the smaller family size in the Western countries as compared to India. ${ }^{8}$
Table 2: Showing the initial Bishop score by parity and intervention.

\begin{tabular}{|c|c|c|c|c|}
$\begin{array}{c}\text { Initial } \\
\text { Bishop } \\
\text { Score }\end{array}$ & $\begin{array}{c}\text { Primi } \\
\mathrm{n}=32\end{array}$ & $\begin{array}{c}\text { Multi } \\
\mathrm{N}=49\end{array}$ & $\begin{array}{c}\text { Primi } \\
\mathrm{N}=30\end{array}$ & $\begin{array}{c}\text { Multi } \\
\mathrm{N}=42\end{array}$ \\
\cline { 3 - 5 } & $\mathrm{N}(\%)$ & $\mathrm{N}(\%)$ & $\mathrm{N}(\%)$ & $\mathrm{N}(\%)$ \\
\hline 0 & $1(3.13)$ & $0(0.00)$ & $2(6.67)$ & $2(4.76)$ \\
\hline 1 & $3(9.38)$ & $3(6.12)$ & $2(6.67)$ & $2(4.76)$ \\
\hline 2 & $7(21.88)$ & 9 & 5 & $2(4.76)$ \\
& & $(18.37)$ & $(16.67)$ & \\
\hline 3 & 10 & 10 & 7 & $7(16.67)$ \\
& $(31.25)$ & $(20.41)$ & $(23.33)$ & \\
\hline 4 & $6(18.75)$ & 10 & 7 & $14(33.33)$ \\
& & $(20.41)$ & $(23.33)$ & \\
\hline 5 & $4(12.50)$ & 13 & 6 & $14(33.33)$ \\
& & $(26.53)$ & $(20.00)$ & \\
\hline 6 & $1(3.13)$ & $4(8.16)$ & $1(3.33)$ & $1(2.38)$ \\
\hline MEAN & $3.03 \pm$ & $3.67 \pm$ & $3.23 \pm$ & $3.79 \pm$ \\
$\pm S D$ & 1.38 & 1.42 & 1.55 & 1.41 \\
\hline
\end{tabular}

As per our hospital protocol, routine induction is done at term (40 weeks gestation). The next most common indication was post term pregnancy $29.63 \%$ and $27.78 \%$ in the Misoprostol and Dinoprostone group respectively. $19.75 \%$ in the Misoprostol group and $13.89 \%$ in the Dinoprostone group were induced in view of PIH. $11.11 \%$ each in both groups were induced for GDM.

In the study conducted by Kolderup et al in 1999, the maximum numbers of inductions in the Misoprostol group $(35 \%)$ were done in view of post-dated pregnancies and $22 \%$ were induced in view of PIH. In the Dinoprostone group (22\%) women were induced in view of PIH and $20 \%$ for post-dated pregnancies. ${ }^{10}$

In the study by Wing et al in 1995, maximum inductions were done in view of oligohydramnios $(54.4 \%)$ in the Misoprostol group and $61.2 \%$ in the Dinoprostone group. 8 Post term pregnancy was the next common indication for induction $-7.4 \%$ in the Misoprostol group and $13.4 \%$ in the Dinoprostone group.

Buser et al in 1997 in their study induced $40.7 \%$ in the Misoprostol group and $29.1 \%$ in the Dinoprostone group in view of post-dated pregnancies and $27.6 \%$ in the Misoprostol group and $29.1 \%$ in the Dinoprostone group for PIH. ${ }^{9}$

In our study, the initial Bishop score at the time of induction in the Misoprostol group was 3.42 and in the Dinoprostone group it was 3.56 with no statistically significant difference. Our study had higher scores compared to the mean pre-treatment score in the study conducted by Buser et al (2.66 in the Misoprostol group and 2.64 in the Dinoprostone group) and Kolderup et al with a mean initial Bishop Score of 2.8 in both the 
groups. ${ }^{9,10}$ This difference can be explained as these studies had included women with a Bishop score of 5 or less.

Table 3: Showing the change in Bishop score after application of the agent by parity.

\begin{tabular}{|c|c|c|c|c|}
\hline Difference & \multicolumn{2}{|c|}{ Misoprostol } & \multicolumn{2}{|c|}{ Dinoprostone } \\
\hline $\begin{array}{l}\text { Bishop } \\
\text { Score }\end{array}$ & $\begin{array}{l}\text { Primi } \\
\mathrm{N}=32\end{array}$ & $\begin{array}{l}\text { Multi } \\
\mathrm{N}=49\end{array}$ & $\begin{array}{l}\text { Primi } \\
N=30\end{array}$ & $\begin{array}{l}\text { Multi } \\
\mathrm{N}=42\end{array}$ \\
\hline $\begin{array}{l}\text { After } 8 \\
\text { Hours }\end{array}$ & $\mathrm{N}(\%)$ & $\mathrm{N}(\%)$ & $\mathrm{N}(\%)$ & $\mathrm{N}(\%)$ \\
\hline 0 & $\begin{array}{c}0 \\
(0.00)\end{array}$ & $0(0.00)$ & $2(6.67)$ & $0(0.00)$ \\
\hline 1 & $\begin{array}{c}2 \\
(6.25)\end{array}$ & $1(2.04)$ & $\begin{array}{c}6 \\
(20.00)\end{array}$ & $\begin{array}{c}5 \\
(11.90)\end{array}$ \\
\hline 2 & $\begin{array}{c}3 \\
(9.38)\end{array}$ & $2(4.08)$ & $\begin{array}{c}5 \\
(16.67)\end{array}$ & $\begin{array}{c}9 \\
(21.43)\end{array}$ \\
\hline 3 & $\begin{array}{c}6 \\
(18.75)\end{array}$ & $8(16.33)$ & $\begin{array}{c}5 \\
(16.67)\end{array}$ & $\begin{array}{c}7 \\
(16.67)\end{array}$ \\
\hline 4 & $\begin{array}{c}9 \\
(28.13)\end{array}$ & 7 (14.29) & $\begin{array}{c}4 \\
(13.33)\end{array}$ & $\begin{array}{c}6 \\
(14.29)\end{array}$ \\
\hline 5 & $\begin{array}{c}4 \\
(12.50)\end{array}$ & $3(6.12)$ & $2(6.67)$ & $\begin{array}{c}3 \\
(7.14)\end{array}$ \\
\hline 6 & $\begin{array}{c}3 \\
(9.38)\end{array}$ & $4(8.16)$ & $2(6.67)$ & $\begin{array}{c}2 \\
(4.76)\end{array}$ \\
\hline 7 & $\begin{array}{c}1 \\
(3.13)\end{array}$ & $0(0.00)$ & $1(3.33)$ & $\begin{array}{c}1 \\
(2.38)\end{array}$ \\
\hline 8 & $\begin{array}{c}1 \\
(3.13)\end{array}$ & $4(8.16)$ & $1(3.33)$ & $\begin{array}{c}1 \\
(2.38)\end{array}$ \\
\hline 9 & $\begin{array}{c}2 \\
(6.25)\end{array}$ & $1(2.04)$ & $0(0.00)$ & $\begin{array}{c}1 \\
(2.38)\end{array}$ \\
\hline 10 & $\begin{array}{c}0 \\
(0.00)\end{array}$ & $0(0.00)$ & $0(0.00)$ & $1(2.38)$ \\
\hline 11 & $\begin{array}{c}0 \\
(0.00)\end{array}$ & $2(4.08)$ & $0(0.00)$ & $\begin{array}{c}0 \\
(0.00)\end{array}$ \\
\hline Delivered & $\begin{array}{c}1 \\
(3.13)\end{array}$ & $\begin{array}{c}17 \\
(34.69)\end{array}$ & $2(6.67)$ & $\begin{array}{c}6 \\
(14.29)\end{array}$ \\
\hline $\begin{array}{c}\text { Mean } \pm \\
\text { SD }\end{array}$ & $\begin{array}{c}4.29 \pm \\
2.04\end{array}$ & $\begin{array}{c}4.97 \pm \\
2.55\end{array}$ & $\begin{array}{c}3.00 \pm \\
2.09\end{array}$ & $\begin{array}{c}3.58 \pm \\
2.26\end{array}$ \\
\hline
\end{tabular}

In the current study, the mean change in the Bishop Score was noted after 8 hours of induction. The women induced with Misoprostol had a mean change of 4.64 while a change of 3.33 was seen in the Dinoprostone group. Both the drugs showed a significant rise in the Bishop Score. However, on comparing the two, Misoprostol was more effective than Dinoprostone in producing cervical changes $(\mathrm{p}<0.05)$.

In the study by Buser et al, Bishop scoring was done after 4 hours in the Misoprostol group and after 6 hours in the women receiving Dinoprostone. ${ }^{9}$ A mean change of 3.53 and 2.7 were noted in the Misoprostol and Dinoprostone groups, respectively, showing a significantly higher change with the use of Misoprostol $(p=0.01)$. Agarwal et al in 2003, assessed the cervix after 6 hours of initiation of therapy in both the groups. ${ }^{12}$ Bishop Score rise was found to be significantly higher in the Misoprostol group than Dinoprostone, 2.98 versus $2.05 \quad(p=0.04)$. The Bishop Score rise in the current study was higher in both the groups, as compared to the other studies. However this change was noted after 8 hours of induction as compared to the 4 hours and 6 hours respectively in the other two studies.

Table 4: Shows the complications during labour by inductive agent.

\begin{tabular}{|l|l|l|}
\hline $\begin{array}{l}\text { Complications } \\
\text { during labor }\end{array}$ & Misoprostol & Dinoprostone \\
\hline $\begin{array}{l}\text { Meconium } \\
\text { stained } \\
\text { Amniotic Fluid }\end{array}$ & $4(4.94)$ & $\mathrm{N}(\%)$ \\
\hline Foetal Distress & $1(1.24)$ & $2(6.94)$ \\
\hline Failed Induction & $0(0.00)$ & $3(4.17)$ \\
\hline Arrest Disorder & $7(8.64)$ & $10(13.89)$ \\
\hline $\begin{array}{l}\text { Hypertonic } \\
\text { Contractions }\end{array}$ & $0(0.00)$ & $1(1.39)$ \\
\hline Scar Dehiscence & $1(1.24)$ & $1(1.39)$ \\
\hline
\end{tabular}

In the current study, $83.95 \%$ women in the Misoprostol group and $72.22 \%$ in the Dinoprostone group delivered with only one dose of the inducing agent. The mean number of doses required were 1.17 and 1.35 in the Misoprostol and Dinoprostone groups respectively which was significantly lesser in the Misoprostol group ( $\mathrm{p}<$ 0.05) similar to the study by Kolderup et al who found that there were significantly fewer doses of Misoprostol used than Dinoprostone with 1.4 Misoprostol doses compared with 2.2 doses of Dinoprostone. ${ }^{10}$ This was different than the findings in the study by Wing et al the mean of doses 2.4 in the Misoprostol group and 2.2 in the Dinoprostone group respectively and Buser et al a mean dose of 1.88 Misoprostol and 1.97 Dinoprostone, though these were not statistically significant. ${ }^{8,9}$

In the current study, the need for oxytocin augmentation for delivery was significantly lower in women receiving Misoprostol for induction similar to the study by Kolderup et al, Agarwal et al. ${ }^{10,11}$

In the present study, there was no significant difference in the caesarean delivery rate between the two groups. $11.11 \%$ in the Misoprostol group and $16.67 \%$ in the Dinoprostone group were delivered by a caesarean section. Same observations were made by other authors. The induction of labour can result in uterine contraction abnormalities such as Tachysystole (is defined as six or more contractions in 10 minutes for 2 consecutive 10 minute period), hypertonus uterus (single contraction with duration of $\geq 2$ minutes), hyperstimulation (tachysystole or hypertonus associated with abnormal FHR pattern) etc. 
Table 5: Shows the distribution of mode of delivery and indications by the induction agent.

\begin{tabular}{|c|c|c|c|}
\hline Mado & $\begin{array}{l}\text { Misoprostol } \\
81\end{array}$ & $\begin{array}{l}\text { Dinoprostone } \\
72\end{array}$ & $\begin{array}{l}\text { P- } \\
\text { value }\end{array}$ \\
\hline & $\mathrm{N}(\%)$ & $\mathrm{N}(\%)$ & \\
\hline NVD & $67(82.72)$ & 47 (65.28) & $<0.05$ \\
\hline $\begin{array}{r}\text { FORCEPS } \\
\text { MSAF } \\
\text { Arrest } \\
\text { Disorder } \\
\text { Fetal } \\
\text { Distress } \\
\text { Previous } \\
\text { LSCS } \\
\text { Heart } \\
\text { Disease }\end{array}$ & $\begin{array}{l}\mathbf{5}(\mathbf{6 . 1 7}) \\
0(0.0) \\
4(80) \\
\\
0(0.0) \\
0(0.0) \\
1(20.0)\end{array}$ & $\begin{array}{l}13 \text { (18.06) } \\
1(7.69) \\
7(53.85) \\
1(7.69) \\
4(30.77) \\
0(0.0)\end{array}$ & $<0.05$ \\
\hline $\begin{array}{r}\text { LSCS } \\
\text { Fetal } \\
\text { Distress } \\
\text { MSAF } \\
\text { Failed } \\
\text { Induction } \\
\text { Arrest } \\
\text { Disorders } \\
\text { Scar } \\
\text { Dehiscence }\end{array}$ & $\begin{array}{l}\mathbf{9 ( 1 1 . 1 1 )} \\
1(11.11) \\
444.44) \\
0(0.00) \\
3(33.33) \\
1(11.11)\end{array}$ & $\begin{array}{l}\text { 12(16.67) } \\
1(8.33) \\
4(33.33) \\
3(25.00) \\
3(25.00) \\
1(8.33)\end{array}$ & $>0.10$ \\
\hline $\begin{array}{r}\text { Puerperal } \\
\text { complication } \\
\text { Pyrexia } \\
\text { PPH }\end{array}$ & $\begin{array}{l}\mathbf{4} \\
2(2.47) \\
2(2.47\end{array}$ & $\begin{array}{l}\mathbf{3} \\
1(1.39) \\
2(2.78)\end{array}$ & \\
\hline
\end{tabular}

In the present study, the mean time taken from the induction to the delivery was 12.40 hours in the Misoprostol group and 16.42 hours in the Dinoprostone group. This was significantly lesser with the use of misoprostol ( $p<0.01$ ) which is similar to the study by Agarwal et al, the mean induction delivery interval was shorter with Misoprostol use; $12.8 \pm 6.4$ hours versus $18.53 \pm 8.5$ hours in the Dinoprostone group $(\mathrm{p}<0.01){ }^{12}$ Buser et al also found a significantly lesser induction to delivery interval in the Misoprostol group (15.8 hours) as compared to the Dinoprostone group (24.2 hours) $(\mathrm{p}<0.01){ }^{9}$ Kolderup et al saw that Misoprostol was associated with significantly fewer hours from the start of induction to delivery (19.8 hours in the Misoprostol group vs. 28.9 hours in the Dinoprostone group; $\mathrm{p}=0.005) .{ }^{19}$ In the study by Wing et al mean induction to delivery interval was 18.35 hours in the Misoprostol group and 26.53 hours in the Dinoprostone group. This interval was significantly shorter in the Misoprostol group. ${ }^{13}$
The present study showed a significantly higher incidence of normal vaginal delivery in the women induced with Misoprostol. $82.72 \%$ women in the Misoprostol group delivered normally as compared to $65.28 \%$ women in the Dinoprostone group; $p<0.05$. The findings are higher than that of in the study by Buser et al (32.8\% in the Misoprostol group and $46.8 \%$ in the Dinoprostone group respectively and Wing et al $75 \%$ of mothers in Misoprostol group and $68.66 \%$ receiving Dinoprostone had a vaginal delivery. ${ }^{8,9}$

In the present study only one case of hypertonicity was observed and it was seen the Dinoprostone group. In the study by Agarwal et al one case (1.6\%) in the Misoprostol group but none in the Dinoprostone group had tachysystole. ${ }^{12}$ Wing et al found a significantly higher incidence of tachysystole in the Misoprostol group as $36.7 \%$ vs. $11.9 \%$ in the Dinoprostone group. ${ }^{8}$ Incidence of Hypertonus $(1.4 \%$ and $3.0 \%$ in the Misoprostol and Dinoprostone groups respectively) and hyperstimulation $(7.4 \%$ in the Misoprostol group and $3.0 \%$ in the Dinoprostone groups) were similar in both groups. The cause of decreased incidence of uterine contraction abnormalities in the present study could be attributed to the increased interval of repeat induction $(8$ hourly versus six hourly or 4 hourly respectively in the two other studies).

There was no significant difference in the incidence of meconium passage with the use of the two drugs in the current study similar to the observations of Kolderup et al and Agarwal et al but Wing et al observed a higher incidence of meconium staining with the use of Misoprostol. ${ }^{8,10,12}$

The present study showed no significant difference in the incidence of abnormal fetal heart rate patterns in the two groups similar to the study by Wing et al which was different from Buser et al and Agarwal observation of a higher incidence of abnormal FHR patterns in the Misoprostol group. ${ }^{9}$

The mean birth weight in the present study was 2981.35 grams in the Misoprostol group and 2981.13 grams in the Dinoprostone group. Buser et al found a mean birth weight of $3435 \mathrm{gm}$ in the Misoprostol group and $3383 \mathrm{gm}$ in the Dinoprostone group of women. ${ }^{9}$ Wing et al observed a mean birth weight of 3273 and 3356 in the Misoprostol and Dinoprostone groups respectively. ${ }^{8}$ No significant difference in the birth weights were observed in both groups in all the above studies.

\section{CONCLUSIONS}

Misoprostol has proved to be better in producing cervical changes and in inducing labor. Nearly every measure of adequacy of labor induction was significantly better with misoprostol use, including time from induction to delivery, lesser requirement of oxytocin augmentation and fewer doses of the drug used. Despite the more rapid 
labor induction course, there was no significant difference in the caesarean rates between the two groups.

\section{ACKNOWLEDGEMENTS}

The authors are thankful to Late Dr. Mary Abraham, Head of Obstetrics and Gynecology and Dr. Saroj Chowdhary, Head of Obstetrics and Gynecology.

\section{Funding: No funding sources}

Conflict of interest: None declared

Ethical approval: The study was approved by the Institutional Ethics Committee

\section{REFERENCES}

1. Parikh SC, Parikh NS. Comparison of local $\mathrm{PGE}_{2}$ gel and I.V. oxytocin in induction of labor. J of Obst Gyn of India. 2001;51:57-9.

2. Fernandes E, Vavilala S. Misoprostol - a miracle drug? Obs \& Gynae Today. 2001;6:530-34.

3. Kleissel HP, VanderRest M, Naftolin F, Glorieux FK, De Leon A. Collagen changes in the human uterine cervix at parturition. Am J Obstet Gynecol. 1978;130:748-53.

4. Harman JH, Kim A. Current trends in cervical ripening and labor induction. Am Fam Physician. 1999;60:477-84.

5. Steiner AL, Creasy RK. Methods of cervical ripening. Clin Obstet Gynecol. 1983;26(1):37.

6. Ramos LS, Peterson S, Delke I, et al. Labor induction with prostaglandin $\mathrm{E}_{1}$ misoprostol compared with Dinoprostone vaginal insert. A randomized trial. Obstet \& Gynecol. 1998;91:401-5.

7. Nunes F, Rodrigues R, Meirinho M. Randomized comparison between intravaginal misoprostol and dinoprostone for cervical ripening and induction of labor. Am J Obstet Gynecol. 1999;181:626-9.

8. Wing DA, Jones MM, Rahall A, Goodwin TM, Paul RH. Misoprostol an effective agent for cervical ripening and labor induction. Am J Obstet Gynecol. 1995;172:1811-6.

9. Buser D, Mora G, Arias F. A randomized comparison between misoprostol and dinoprostone for cervical ripening and labor induction in patients with unfavourable cervices. Obstet Gynecol. 1997;89:581-5.

10. Kolderup L, McLean L, Grullon K, Safford K, Kilpatrick SJ. Misoprostol is more efficacious for labor induction than prostaglandin $\mathrm{E}_{2}$, but is it associated with more risk? Am J Obstet Gynecol. 1999; 180:1543-50.

11. Danielian P, Porter B, Ferri N, Summers J, Templeton A. Misoprostol for induction of labor at term: a more effective agent than dinoprostone vaginal gel. Br J Obstet Gynecol. 1999;106:793-7.

12. Agarwal N, Gupta A, Kriplani A, Bhatla N, Parul. Six hourly vaginal misoprostol versus intracervical dinoprostone for cervical ripening and labor induction. J Obstet Gynecol Res. 2003;29(3):147-51.

Cite this article as: D'souza AS, Samuel CJ, Katumalla FS, Garg G, Goyal S. A randomized comparison between misoprostol and dinoprostone for cervical ripening and labor induction in patients with unfavorable cervices. Int J Reprod Contracept Obstet Gynecol 2015;4:1522-8. 